\title{
Dynamic Rupture through a Branched Fault Configuration at Yucca Mountain, and Resulting Ground Motions
}

\author{
by Elizabeth L. Templeton, ${ }^{*}$ Harsha S. Bhat, Renata Dmowska, and James R. Rice
}

\begin{abstract}
We seek to characterize the likelihood of multiple fault activation along a branched normal-fault system during earthquake rupture using dynamic finite element analyses. This is motivated by the normal faults in the vicinity of Yucca Mountain, Nevada, a potential site for a high-level radioactive waste repository. The Solitario Canyon fault (SCF), a north-south trending fault located approximately $1 \mathrm{~km}$ west of the crest of Yucca Mountain, is the most active of these faults. Based on the results of previous branching work by Kame et al. (2003), branch activation in the hanging wall of a normal fault such as the SCF may be possible for fast ruptures propagating near the Rayleigh-wave speed at the branch junction. Dynamic branch activation along a splay of the SCF during a seismic event could have important effects on the rupture velocity and resulting ground motions at the proposed repository site. We consider elastic as well as a pressure-dependent elastic-plastic response of the off-fault material. We find that based on the regional stress state in the area, the only likely candidates for branch activation in the hanging wall of the SCF are more steeply westward dipping intrablock splay faults. We also find that the rupture velocity for an earthquake propagating updip along the SCF must reach supershear speeds in order for dynamic branch activation to occur. Branch activation can have significant effects on the ground motions at the proposed repository site, $1 \mathrm{~km}$ away from the SCF beneath the crest of Yucca Mountain, causing the repository site to experience a second peak in large vertical particle velocities. Elastic-plastic response near the branch junction reduces peak ground velocities and accelerations at the proposed repository site.
\end{abstract}

\section{Introduction}

We seek to characterize the likelihood of multiple fault activation along a branched normal-fault system during earthquake rupture using dynamic finite element analyses. This is motivated by the normal faults in the vicinity of Yucca Mountain, Nevada. Yucca Mountain is located along the western boundary of the Nevada Test site at approximate coordinates of $36^{\circ} 50^{\prime} \mathrm{N}, 116^{\circ} 28^{\prime} \mathrm{W}$ (Fig. 1) and has been identified as a potential site for a high-level radioactive waste repository. The topography of the Yucca Mountain area is formed by block-bounding normal faults, such as the Solitario Canyon fault (SCF) (Potter et al., 1999, 2004). Those faults experienced hundreds of meters of Neogene normalsense displacement (Scott and Bonk, 1984; O'Neill et al., 1992; Dickerson and Spengler, 1994; Simonds et al., 1995; Day, Dickerson, et al., 1998; Day, Potter, et al., 1998) and small amounts of Quaternary offsets (Simonds et al., 1995). The SCF is the most active of these faults and formed the west-facing scarp of Yucca Mountain (Stepp

\footnotetext{
*Now at ExxonMobil Upstream Research Company, Houston, Texas.
}

et al., 2001). Dynamic branch activation along a splay of the SCF during a seismic event could have important effects on the rupture velocity and resulting ground motions at the proposed repository site.

The criteria for dynamic branch activation in natural fault systems have been extensively studied (Poliakov et al., 2002; Kame et al., 2003; Oglesby et al., 2003; Bhat et al., 2004; Oglesby et al., 2004, Bhat et al., 2007; Duan and Oglesby, 2007). Poliakov et al. (2002) identified locations of possible branch activation by investigating the dynamic stress field surrounding a rapidly propagating semi-infinite nonsingular mode II distance-weakening shear rupture in an elastic material. They suggested that the prestress state and rupture velocity control the location of zones where the crack-tip stress field could violate a Mohr-Coulomb (MC) failure criterion and potentially nucleate rupture along a preexisting branch. Kame et al. (2003), Bhat et al. (2004), and Fliss et al. (2005) extended the work of Poliakov et al. (2002) by including preexisting branch faults to investigate, in the framework of slip-weakening modeling of spontaneous rupture, how rupture velocity, prestress state, and 


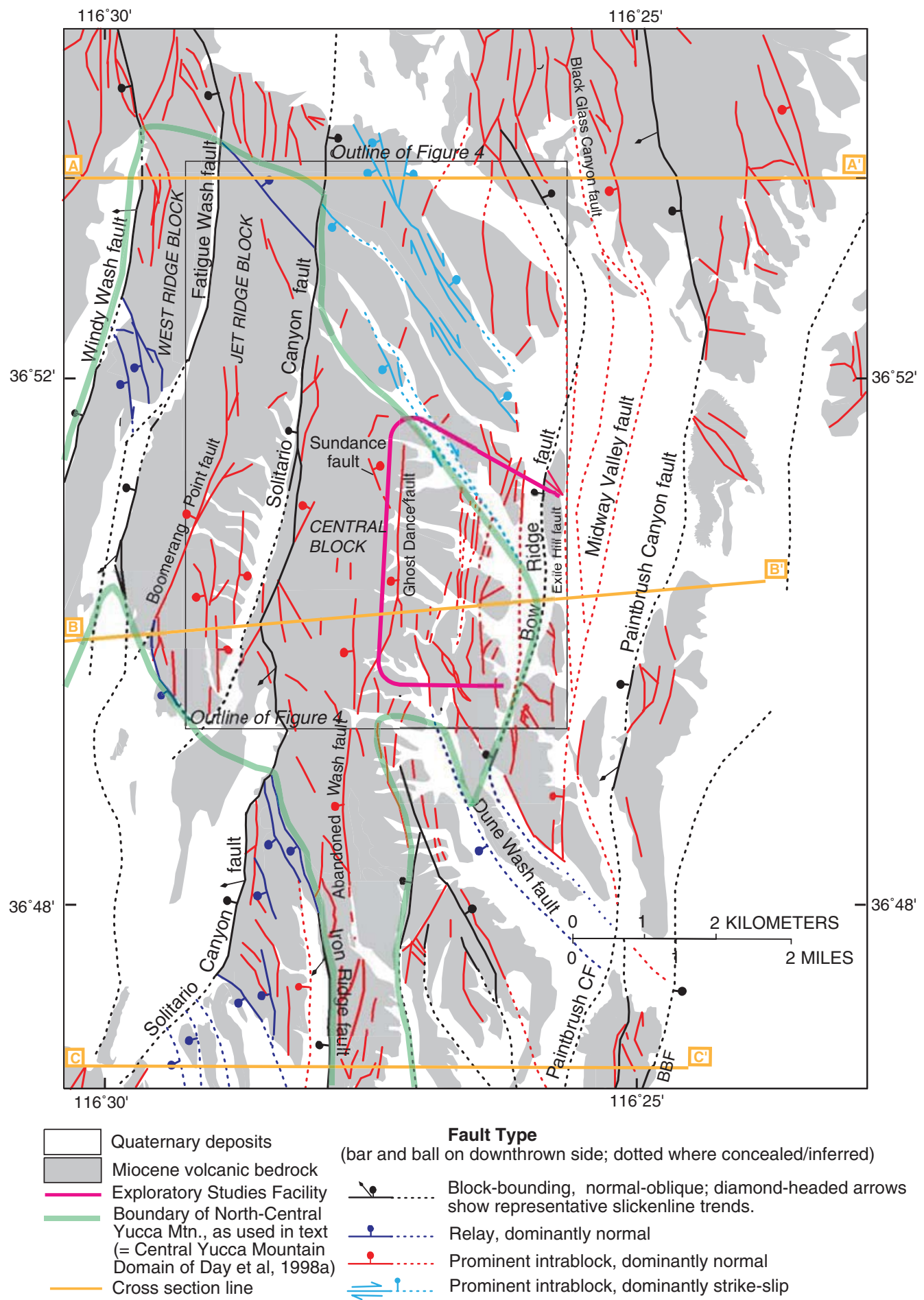

Figure 1. Faults in the vicinity of Yucca Mountain mapped by Potter et al. (2004). The color version of this figure is available only in the electronic edition.

angle of the preexisiting branch control dynamic branch activation. Those studies focused on explaining branch activation during recent large earthquakes such as the 1992 Landers earthquake (Fliss et al., 2005), the 2002 Denali earthquake (Bhat et al., 2004), the 1971 San Fernando, the 1985 Kettleman Hills, and the 1979 Imperial Valley earthquakes (Kame et al., 2003). The numerical studies can be used to make predictions about dynamic path selection of rupture propagation for frictional slip-weakening rupture based on fault geometry and prestress state for a range of potential rupture speeds. Multicycle simulations of dynamic branch activation performed by Duan and Oglesby (2007) 
showed that highly nonuniform stress will develop in the vicinity of the branch junction and can have strong effects on branching behavior. Based on the results of Kame et al. (2003), branch activation in the hanging wall of a normal fault, such as the SCF, may be possible for fast ruptures propagating near the Rayleigh-wave speed at the branch junction.

Andrews et al. (2007) explored limits on ground motions that can be produced at the repository site by investigating dynamic rupture scenarios along the SCF. The authors considered the stress available at seismogenic depths in the crust, MC yield strength of the rocks, and the maximum ground motion consistent with observations of historical fault slip at the surface. By including MC yielding Andrews et al. (2007) were able to limit the horizontal peak ground velocity (PGV) to a value less than the probabilistic seismic hazard assessment (PSHA) prediction for PGV at low probabilities of exceedance by Stepp et al. (2001). The physical limit for vertical ground motions found by Andrews et al. (2007) was larger than the PSHA prediction for very low probabilities due to supershear rupture along the SCF. However, currently there are no observations of supershear rupture during normal-faulting earthquakes.

We use dynamic finite element analyses to build on the work of Kame et al. (2003) and Bhat et al. $(2004,2007)$ on the factors controlling branch fault activation to determine whether branch activation is likely for the fault geometry and stresses in the faults in the vicinity of Yucca Mountain. Recent studies by Andrews (2005), Ben-Zion and Shi (2005), and Templeton and Rice (2008) have shown that the stresses produced during dynamic rupture can violate an MC or Drucker-Prager (DP) yield criterion and that the energy dissipated off-fault by inelastic deformation can slow rupture propagation and potentially limit ground motions. Following those and the work of Andrews et al. (2007), who included MC yielding in studies of dynamic rupture along the SCF, we include a yield criterion for elastic-plastic deformation in our investigation of branch activation at the SCF.

First, we perform simulations with constant prestress state like those of Kame et al. (2003) to characterize branch fault activation for sub-Rayleigh and supershear rupture for a range of branch angles consistent with normal-fault splays in the vicinity of Yucca Mountain for both elastic and elasticplastic off-fault material response. Based on those results, we choose several successful constant prestress branch activation cases to model in detail including depth-dependent stresses and surface effects, as well as inelastic off-fault response. For those scenarios we provide ground motions at the repository site. The results show the branch activation is unlikely for sub-Rayleigh rupture along the SCF but possible for supershear rupture at the branch junction. The horizontal and vertical PGVs and peak ground accelerations at the repository site are decreased by off-fault inelastic energy dissipation.

\section{Geologic Setting and Fault Geometry at Yucca Mountain, Nevada}

Potter et al. (2004) describe the geometry of the Yucca Mountain region as consisting of (1) block-bounding normal faults, spaced 1-4 km apart; (2) northwest-striking relay faults linking displacement between the block-bounding faults; (3) discontinuous intrablock faults; and (4) mesoscopic fracture network. The major block-bounding faults, which include the SCF, Windy Wash fault, and Fatigue Wash fault, were active at Yucca Mountain during and after eruption of the 12.8-12.7 Ma Paintbrush group. Potter et al. $(1999,2004)$ map and provide cross-sectional interpretations of the faults in the area surrounding Yucca Mountain, as shown here in Figures 1 and 2. The cross section across $\mathrm{BB}^{\prime}$ shows that the SCF is bordered on the west by a series of more steeply westward dipping normal faults. Figure 3 shows an alternative cross-sectional interpretation proposed by Brocher et al. (1998) based on seismic reflection studies of the area. Brocher et al. (1998) suggest that the SCF is the last westward dipping fault and is bordered to the west by normal faults conjugate to the SCF dipping to the east bounded by Bare Mountain.

The two different cross-sectional maps by Potter et al. (2004) and Brocher et al. (1998) suggest two different branch fault scenarios. West-dipping strata forming coherent

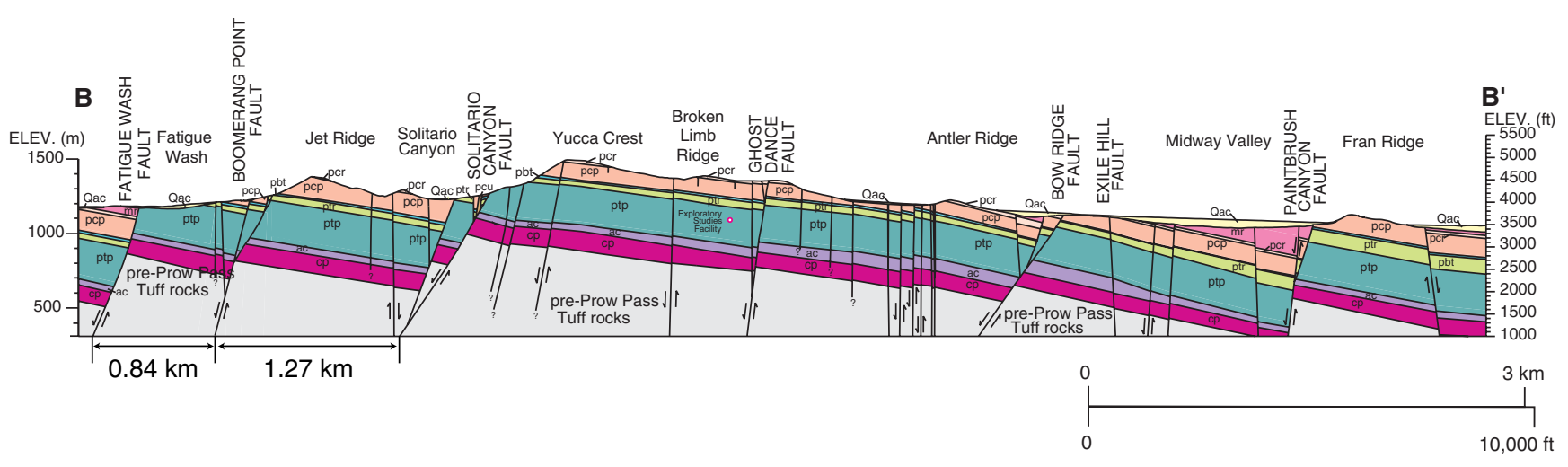

Figure 2. Cross-sectional view of faults in the vicinity of Yucca Mountain showing steeply westward dipping normal faults west of the SCF (Potter et al., 2004). The color version of this figure is available only in the electronic edition. 
(a)

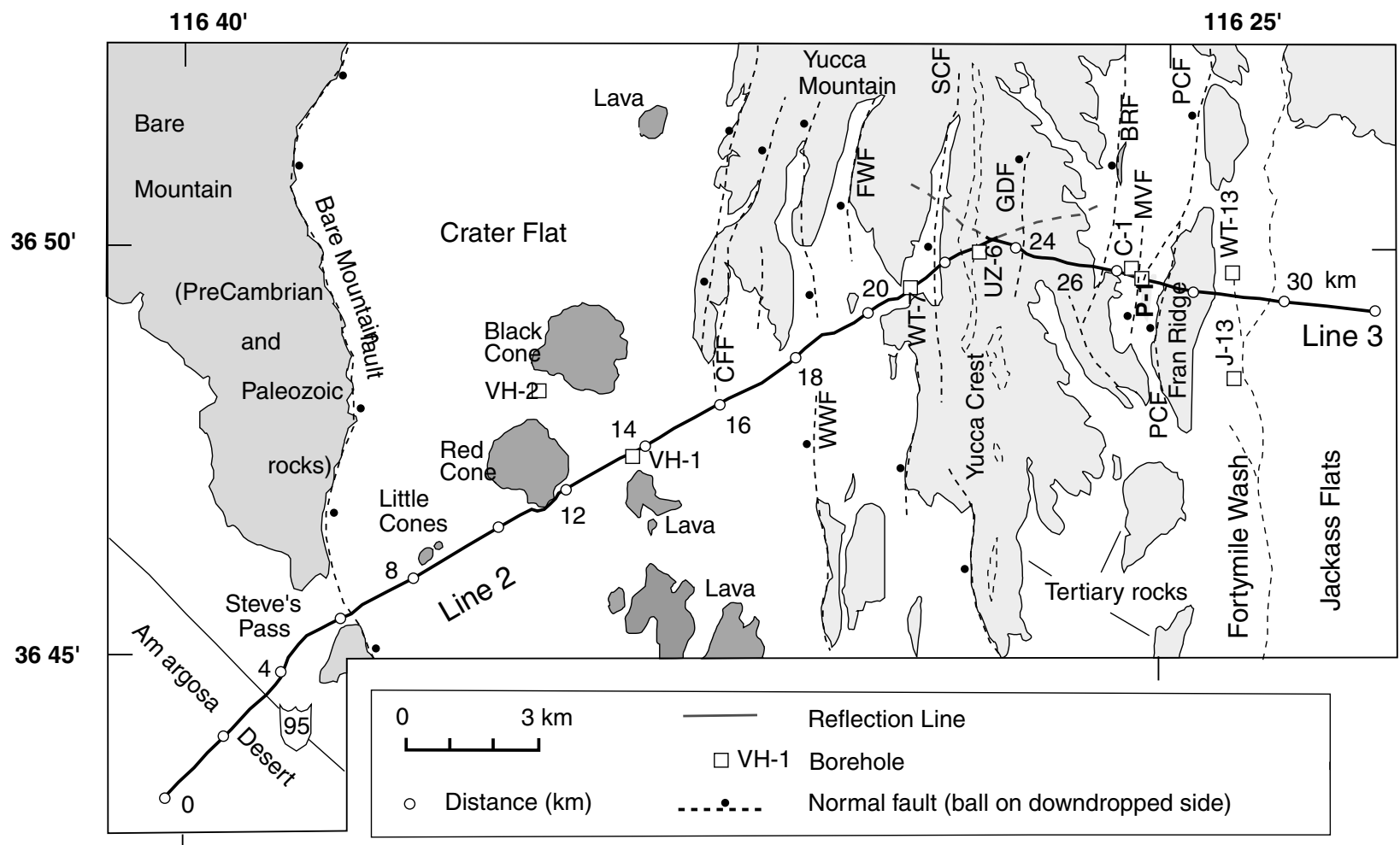

(b)

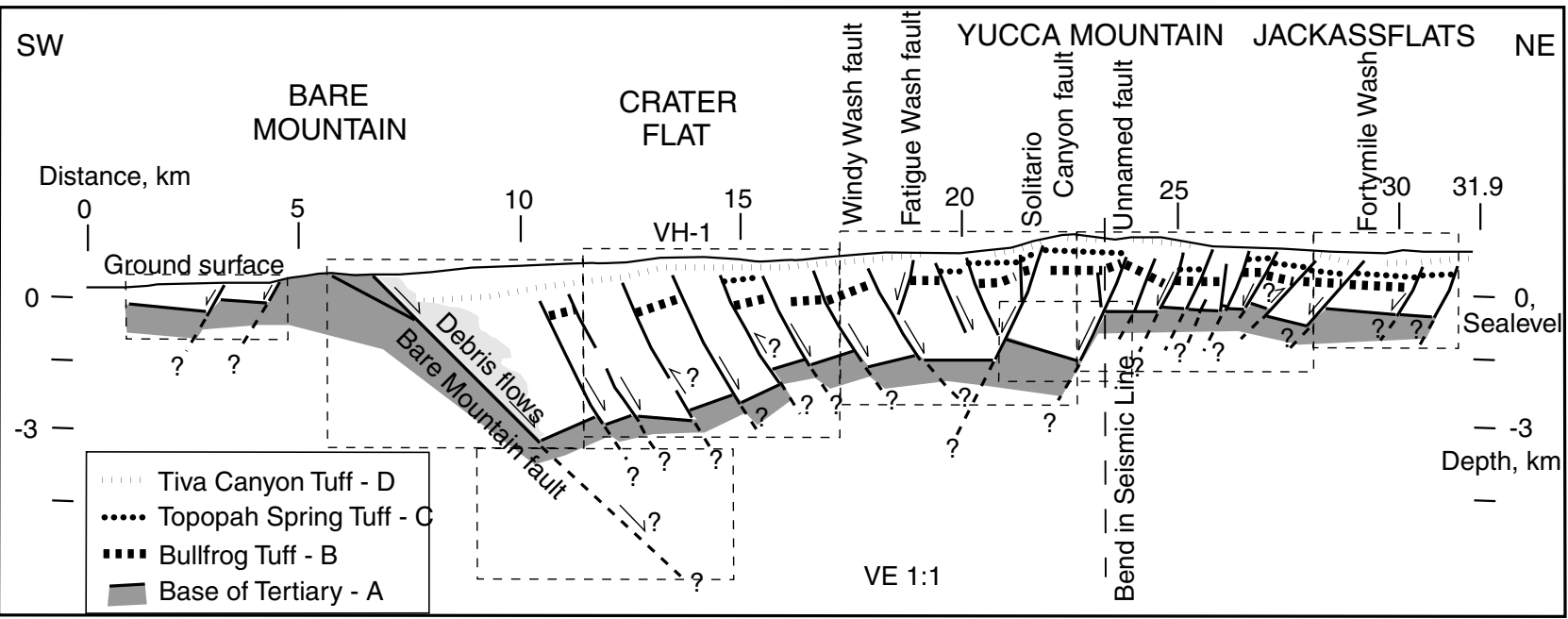

Figure 3. (a) Map showing relation of seismic lines 2 and 3 to Yucca Mountain from Brocher et al. (1998). (b) Cross-sectional view of faults in the vicinity of Yucca Mountain showing eastward dipping normal faults west of the SCF by Brocher et al. (1998) based on their interpretation of seismic lines 2 and 3.

structural panels were observed by Scott and Bonk (1984), Scott and Wernicke (1990), and Potter et al. $(1999,2004)$ in the hanging walls of the SCF, a block-bounding fault, bounded on its western side by steeply dipping faults that splay off of it at depth. The Boomerang fault, a westward dipping fault west of the SCF, is one of the larger intrablock normal faults in the vicinity of Yucca Mountain. The intrablock faults, mapped by Day, Dickerson, et al. (1998), Day, Potter, et al. (1998), and Scott and Bonk (1984) display tens of meters of west side down displacement, in contrast to the major block-bounding faults that display hundreds of meters of displacement. Based on surface dips, the Boomerang fault could intersect the SCF at a depth of $3 \mathrm{~km}$ with a branch angle of approximately $20^{\circ}$. The Windy Wash fault as interpreted by Brocher et al. (1998) is an eastward dipping normal fault conjugate to the SCF. According to that interpretation, the Windy Wash fault would intersect the SCF at approximately $3 \mathrm{~km}$ with a branch angle of $60^{\circ}$.

The stress magnitudes and orientation at the Nevada Test site have been extensively studied and are summarized by Carr (1974) and Zoback abd Zoback (1980). The stresses within the site are consistent with normal and strike-slip 
faulting, with the least principal stress direction varying from northwest to west-northwest. The stresses at Yucca Mountain were measured with a series of hydraulic fracturing stress measurements and acoustic borehole televiewer measurements in two wells at Yucca Mountain by Stock et al. (1985). The hydraulic fracturing study by Stock et al. (1985) indicates that both the least and greatest horizontal principal stresses $\left(\sigma_{h}\right.$ and $\left.\sigma_{H}\right)$ are less than the vertical stress $\left(\sigma_{v}\right)$ with the least horizontal principal stress oriented $\mathrm{N} 65^{\circ}$ $\mathrm{W}$. Under the stresses observed during the hydraulic fracturing study, faults striking at $\mathrm{N} 25^{\circ} \mathrm{E}$ dipping either east or west between $60^{\circ}$ and $67^{\circ}$, the orientation of the block-bounding faults mapped in the vicinity of Yucca Mountain, are favorable for slip with friction coefficients ranging from 0.6 to 1.0 (Stock et al., 1985).

\section{Strength of Fault and Adjoining Material}

\section{Fault Constitutive Behavior}

We use the slip-weakening formulation, proposed by Ida (1972) and Palmer and Rice (1973), as the failure criterion to describe the evolution of shear strength with slip along predefined faults. The law assumes that frictional strength, at fixed normal stress, depends only on the amount of slip, $\Delta u$, that has occurred on the fault. In the simple case of linear degradation of frictional strength with slip, the frictional strength of the fault can be written as

$$
\tau=f(\Delta u) \times\left(-\sigma_{n}\right),
$$

where $f(\Delta u)$ describes the evolution of the coefficient of friction with increasing slip,

$$
f(\Delta u)= \begin{cases}f_{s}-\left(f_{s}-f_{d}\right) \frac{\Delta u}{D_{c}}, & \Delta u<D_{c} \\ f_{d}, & \Delta u>D_{c} .\end{cases}
$$

Here, $D_{c}$ is the critical slip-weakening distance. The peak and residual shear strength, $\tau_{p}=f_{s}\left(-\sigma_{n}\right)$ and $\tau_{r}=$ $f_{d}\left(-\sigma_{n}\right)$ are both proportional to a static or dynamic coefficient of friction times the fault-normal stress $\left(-\sigma_{n}\right)$. If pore fluid is present, the fault-normal stress should be regarded as an effective stress. The proximity of the initial resolved shear stress along a fault to peak and residual fault strength is defined by the seismic $S$ ratio, $S=\left(\tau_{p}-\tau^{0}\right) /\left(\tau^{0}-\tau_{r}\right)$. This slip-weakening law has been used in previous studies of branching including the work of Kame et al. (2003) and was used to successfully model experimental observations of branch activation in homalite plates (Templeton et al., 2009). This formulation has also been used by Andrews et al. (2007) to investigate physical limits on ground motions at Yucca Mountain. An important physical length scale associated with this friction law is the slip-weakening zone size, $R$. This is the length along the crack interface over which frictional strength decreases from a peak to residual. At low speeds, in the limit of large seismic $S$ ratio and for elastic off-fault material behavior, the size of this zone is given by $R_{0}$ :

$$
R_{0}=\frac{9 \pi}{32(1-\nu)} \frac{G D_{c}}{\left(f_{s}-f_{d}\right)\left(-\sigma_{n}\right)},
$$

where $G$ is the shear modulus and $\nu$ is the Poisson ratio. The slip-weakening zone size, $R$, decreases from $R_{0}$ at zero speed with increasing rupture velocity and propagation length. Andrews (1976) observed in numerical simulations that when the seismic $S$ ratio is sufficiently low (initial shear stress along the fault is very close to peak strength), $S<1.77$, the rupture propagation speed can transition from the sub-Rayleigh to the supershear regime by formation of a daughter crack ahead of the main rupture.

Andrews et al. (2007) investigated several combinations of static and dynamic frictional coefficients in order to identify how stress drop from an initial resolved shear stress of $\tau^{0} /\left(-\sigma_{n}\right)=0.55$ contributes to ground motions and total slip. We use two of the combinations used by Andrews et al. (2007), a low stress-drop case with $f_{s}=0.76$ and $f_{d}=0.448$ producing sub-Rayleigh rupture and a high stress-drop case with $f_{s}=0.7$ and $f_{d}=0.1$ producing supershear rupture, to investigate the likelihood of branch activation along a splay of the SCF. With the initial resolved shear stress along the fault of $\tau^{0} /\left(-\sigma_{n}\right)=0.55$, the low stress-drop scenario has $S=2.05$ and the high stress-drop scenario has $S=0.33$, so supershear ruptures will be possible for that latter case.

\section{Off-Fault Constitutive Behavior}

Previous work by Andrews (2005), Ben-Zion and Shi (2005), Andrews et al. (2007), and Templeton and Rice (2008) has shown that energy dissipated off-fault by inelastic processes can slow rupture propagation and potentially limit ground motions. Those studies used MC or DP yield conditions for elastic-plastic response of the fault-bordering rocks. We include elastic-plastic response in our study of branch fault activation. A pressure-dependent elastic-plastic yield criterion, as described in Templeton and Rice (2008), is used. This criterion can be understood in terms of the behavior of a material subjected to a hydrostatic compressive stress, $-\sigma$ (with $\sigma$ positive in tension), and a shear stress, $\tau$. The relationships between stress and strain increments for a material with linear elastic isotropy can be written as

$$
\begin{aligned}
d \gamma & =\frac{d \tau}{G}+\frac{1}{h}(d \tau+\mu d \sigma), \\
d \epsilon & =\frac{d \sigma}{K}+\frac{\beta}{h}(d \tau+\mu d \sigma),
\end{aligned}
$$

during elastic-plastic response, where $G, K$, and $h$ are the shear, bulk, and plastic hardening moduli, respectively. A plastic strain increment is $d^{p} \gamma=d \gamma-d \tau / G$. The dilatancy factor, $\beta$, is the ratio of an increment in volumetric plastic strain to an increment in shear plastic strain: $d^{p} \epsilon=\beta d^{p} \gamma$. The description can be generalized for arbitrary stress states following Rudnicki and Rice (1975) by taking $\sigma=\sigma_{k k} / 3$ 
and $\tau=\bar{\tau} \equiv \sqrt{(1 / 2) s_{i j} s_{i j}}$, the second invariant of the deviatoric stress $s_{i j}=\sigma_{i j}-\delta_{i j} \sigma_{k k} / 3$. The yield condition proposed by Drucker and Prager (1952), a pressure-dependent modification of the Huber-von Mises yield criterion, is a simple choice for describing granular or cracked materials. The DP yield criterion (Drucker and Prager, 1952; Lubliner, 1990, ch. 3.3.3) is given by

$$
\bar{\tau}+\mu\left(\sigma_{k k} / 3\right)=b
$$

and shown in Figure 4. Here $b$ is the cohesion, or shear strength, at zero mean normal stress. A more detailed description of the elastic-plastic formulation, including the treatment of plastic dilational and shear straining, can be found in appendix 2 of Templeton and Rice (2008), and the effects of pore-fluid infiltration are discussed by Viesca et al. (2008). The effects of pore-fluid pressure changes can be included in this formulation by transforming all present constitutive parameters into new parameters by rules based on Rudnicki (1984a,b, 2000) and given in Viesca et al. (2008).

In plane strain, the DP yield criterion approximates the $\mathrm{MC}$ criterion, which takes the form

$$
\max _{\text {all orientations }}\left[\tau+(\tan \phi)\left(\sigma_{n}\right)\right]=c,
$$

where $\tau$ and $\left(-\sigma_{n}\right)$ are the shear and normal traction on any plane, $\tan \phi$ is the internal friction coefficient, and $c$ is the cohesion. The DP and MC criteria coincide exactly for $2 \mathrm{D}$ stress states like those used here for the initial stress state with the out of plane principal stress given by $\sigma_{z z}=$ $\left(\sigma_{x x}+\sigma_{y y}\right) / 2$. For such stress states, the cohesion and friction coefficients are related by $b=c \cos \phi$ and $\mu=\sin \phi$, which we take to define $b$ and $\mu$ here. Although both criteria are idealizations and neither is fully suitable for describing the inelastic behavior of rocks (Colmenares and Zoback,

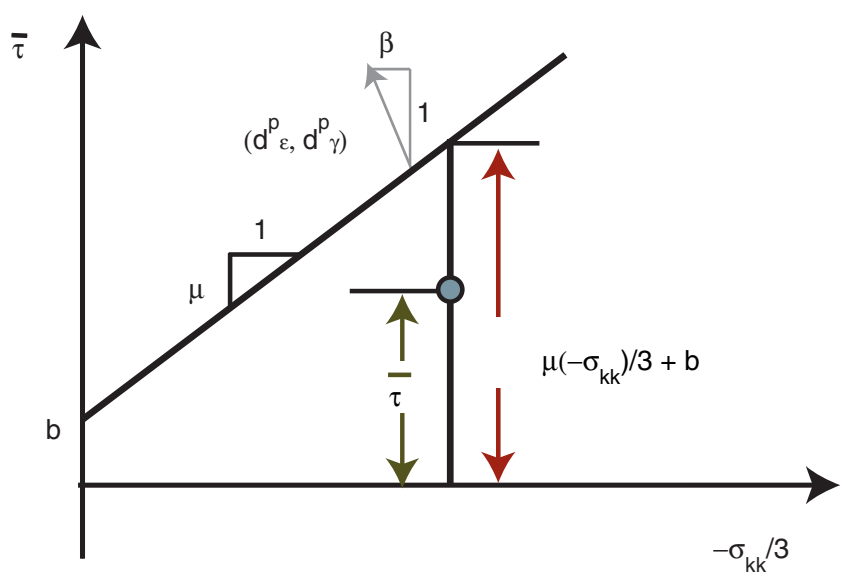

Figure 4. DP yield criterion used to include inelastic off-fault material response. The color version of this figure is available only in the electronic edition.
2002; Davis and Selvadurai, 2002), we use the DP description, which is widely adopted in geomechanics applications.

Rudnicki and Rice (1975) showed that this type of yield description can be prone to strain localization and identified combinations of $\mu, \beta$, and $h$ that would allow strain localization as a function of stress state. Templeton and Rice (2008) found that localized shear bands can form during the numerically simulated dynamic rupture processes, especially in nondilatant, nonhardening materials. However, they found that the dynamics of rupture propagation were little different from what was obtained when they increased the assumed plastic hardening modulus $h$ above $h_{c r}$ to preclude such localizations and obtain a locally smooth and presumably pointwise convergent numerical solution.

\section{Numerical Models and Procedure}

We use the explicit dynamic finite element method, in the form of ABAQUS/Explicit (ABAQUS, 2005) to investigate branch activation along the extensional side of a normal fault dipping at $60^{\circ}$. A $2 \mathrm{D}$ rectangular model composed of three-noded linear plane-strain elements (type CPE3 in ABAQUS) was used. The elements were arranged in a cross-triangle pattern, as illustrated in Figure 5, to set the angle of the branching junction. As noted in Andrews et al. (2007), a 2D plane-strain model of the east-west vertical cross section is reasonable because the crest of Yucca Mountain runs north-south and with little variation in east-west structure for several kilometers around the repository.

Figure 6 shows the two finite element models developed for use in this study. A model with absorbing elements surrounding the entire mesh, as shown in Figure 6a, was used to investigate dynamic rupture along a fault in a homogeneous material for constant prestress states and a range of branch angles. The absorbing elements are designed to minimize reflections from the boundaries. They work by introducing normal and shear tractions on the boundary of the finite element mesh that are proportional to the normal and shear components of velocity at the boundary, with damping constants chosen as the wave impedance factors to minimize reflections of dilational and shear-wave energy. Forces are applied between the boundary of the plane-strain elements and the absorbing elements consistent with the prescribed initial stress state. For the constant stress model, the element

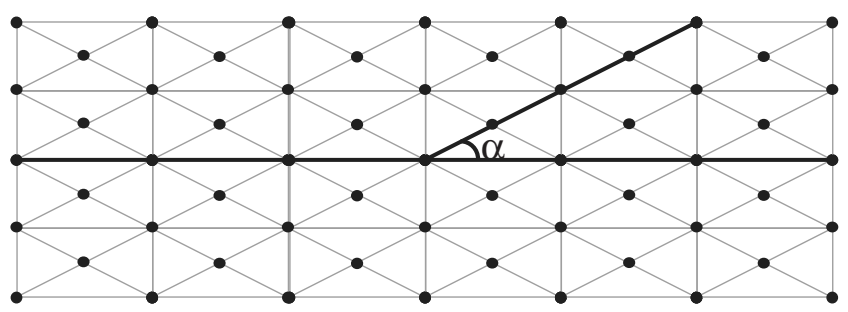

Figure 5. Schematic of element layout surrounding the branch junction. A set of duplicate nodes defines the faults. 
(a)

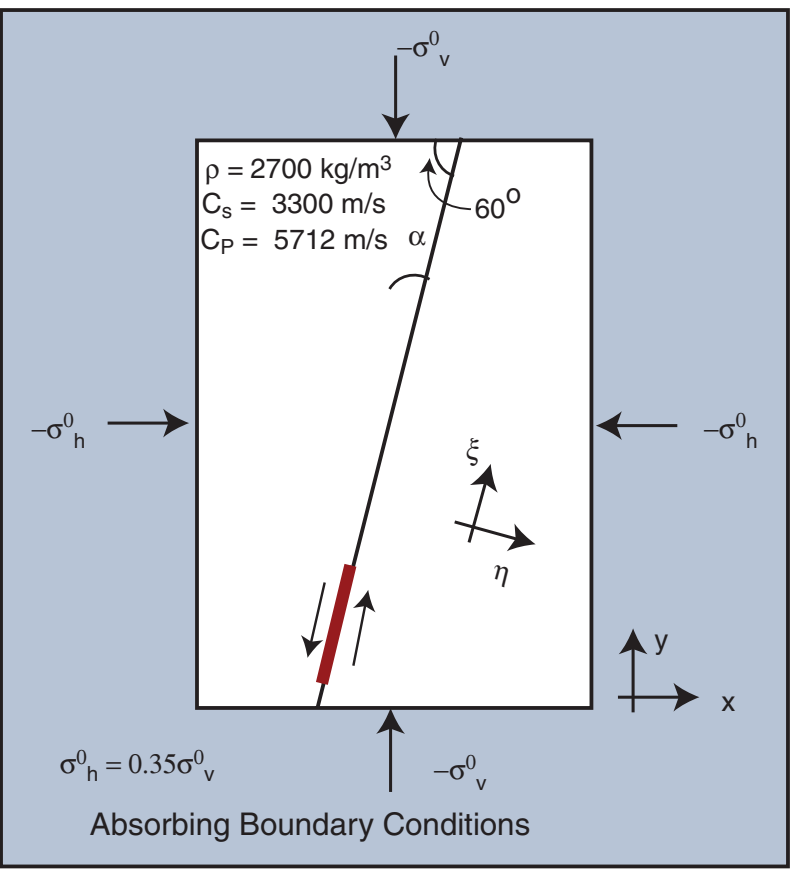

(b)

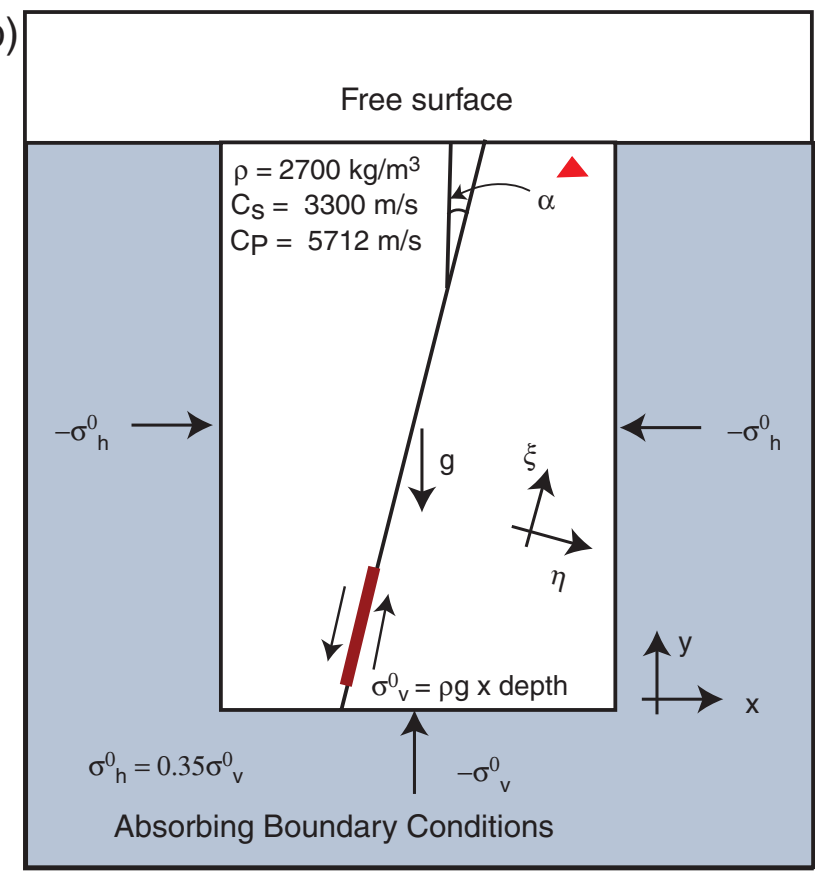

Figure 6. Schematic of finite element models used for the (a) constant prestress branching study and (b) depth-dependent prestress branching study with free surface effects. In the depth-dependent model, time histories of velocities and accelerations are reported at the station indicated in (b) at a $200 \mathrm{~m}$ depth $1 \mathrm{~km}$ east of the main fault. The color version of this figure is available only in the electronic edition.

size along the fault was chosen so that the slip-weakening zone size would be well resolved, with $\Delta \xi=R_{0} / 20$.

A model with a free surface and stresses that increase with depth due to gravity and overburden load so that $\sigma_{v}^{0}=\rho g \times$ depth, with the geometry shown in Figure $6 \mathrm{~b}$, was used to study the effects of branch activation on ground motions at the proposed repository site. The free surface is horizontal in the depth-dependent stress model, and topographic effects are neglected. In that depth-dependent stress model, an element size of $14 \mathrm{~m}$ was used to model rupture initiating at a depth of $10 \mathrm{~km}$, with a resolution of the slipweakening zone of $\Delta \xi=R_{0} / 5$ at $8 \mathrm{~km}$ depth.

In both models, material properties are constant with $\rho=$ $2700 \mathrm{~kg} / \mathrm{m}^{3}, c_{S}=3300 \mathrm{~m} / \mathrm{sec}$, and $c_{P}=5712 \mathrm{~m} / \mathrm{sec}$. The initial stress state imposed has vertical and horizontal principal stresses, with a vertical most compressive principal stress, which means that the angle of most compressive stress to the fault is $\Psi=30^{\circ}$. The least compressive principal stress, $\sigma_{h}^{0}$, is set to $\sigma_{h}^{0}=0.35 \sigma_{v}^{0}$ so that a fault dipping at $60^{\circ}$ will have a resolved shear stress of $\tau^{0} /\left(-\sigma_{n}^{0}\right)=0.55$. We specify an initial out of plane stress of $\sigma_{z z}^{0}=\sigma_{H}^{0}=\left(\sigma_{v}^{0}+\sigma_{h}^{0}\right) / 2$.

A set of duplicate nodes (split nodes) is present along the predefined faults, and a split-node contact procedure is used to prescribe the weakened shear strength resulting from slip during rupture along the fault. During slip, tangential forces are applied at each node along the fault, consistent with the current shear strength of the fault described in equations (1) and (2). Details of the implementation can be found in Templeton and Rice (2008). At the junction, opening is pro- hibited so that slip is constrained to be in the direction of slip along the primary fault (the SCF). This constraint was imposed in previous studies of branching using the boundary integral equation method by Kame et al. (2003); however, this is a simplicity introduced for numerical computations that eliminates the possibility of opening and neglects evolution of the junction geometry.

To nucleate the dynamic rupture, we impose an initial shear stress distribution consistent with a slip-weakening shear crack like in Kame et al. (2003) and Bhat et al. (2004) along a portion of the fault of length $L_{c}^{\prime}$. The length of the nucleation zone, $L_{c}^{\prime}$, is chosen somewhat greater than the minimum nucleation size length, calculated by Palmer and Rice (1973) and given here for $\nu=0.25$ as

$$
L_{c} \approx \frac{16}{3 \pi} \frac{G \mathcal{G}}{\left(\sigma_{x y}^{0}-\tau_{r}\right)^{2}}=\frac{64}{9 \pi^{2}}\left(\frac{\tau_{p}-\tau_{r}}{\sigma_{x y}^{0}-\tau_{r}}\right)^{2} R_{0}
$$

for the large $S$ limit coinciding with singular elastic crack mechanics with small scale yielding. The initial alteration in shear stress causes a stress concentration at both tips of the nucleation zone that initiates dynamic shear rupture from the ends of the nucleation zone. To implement this numerically, we first determine an initial static equilibrium configuration for a static crack of length $L_{c}^{\prime}$ as described in Kame et al. (2003). We then determine the shear stresses within that zone. Nodal tangential forces are applied within the nucleation zone consistent with the shear stresses determined for the static crack. 


\section{Results and Discussion}

We investigate the likelihood of branch fault activation for splay faults on the extensional side of the SCF, with a range of splay fault angles from small angles for more steeply westward dipping splays to larger angles for conjugate eastward dipping faults. First, we repeat simulations with constant prestress state like those of Kame et al. (2003), using the model shown in Figure 6a to characterize branch fault activation, for $\Psi=30^{\circ}$, for sub-Rayleigh and supershear rupture for range of branch angles ranging from $10^{\circ}$ to $60^{\circ}$. Then we include elastic-plastic off-fault material response to determine how plastic deformation alters the criteria for branch fault activation. Using the results of the constant prestress branching study, we choose geometry and stress drop likely to activate the branch for full depthdependent study using the model shown in Figure $6 \mathrm{~b}$.

\section{Constant Prestress Branching Results}

The most compressive stress direction is vertical, as determined by Stock et al. (1985) so that the direction of most compressive stress, $\Psi$, to the SCF, which dips at $60^{\circ}$ to the west, is $\Psi=30^{\circ}$. For $\Psi=25^{\circ}$, Kame et al. (2003) found that no long-running branch activation occurred, although at high speeds rupture started along the branch but soon stopped. Using two combinations of static and dynamic friction coefficients, we investigate two rupture velocities at the branch junction. For $S=2.05$, the rupture velocity will be in the sub-Rayleigh regime, but for the high stress-drop case,
$S=0.33$ and a transition to supershear rupture occurs. First, we examine the likelihood of dynamic branch activation for a branch in an elastic material, and next we include the possibility of inelastic material response.

Elastic Off-Fault Material Response. Figure 7 summarizes dynamic branch activation for branch angles, $\alpha$, ranging from $10^{\circ}$ to $60^{\circ}$. For the low stress-drop case $\left(\Delta \tau /\left(-\sigma_{n}\right)=0.10\right)$, rupture velocity reaches $0.86 c_{s}$ at the branching junction. For all branch angles $\alpha \leq 60^{\circ}$, rupture continues along the main fault past the branch junction, with brief activation along the branched fault. The length of branch activation decreases from $5.3 R_{0}$ to $1 R_{0}$ as $\alpha$ increases from $10^{\circ}$ to $60^{\circ}$. For the high stress-drop case $\left(\Delta \tau /\left(-\sigma_{n}\right)=0.24\right)$, the rupture transitions to supershear, reaching $1.6 c_{s}$ at the branch junction. Supershear branch activation with rupture continuation along the main fault occurs for branch angles of $10^{\circ}$ and $15^{\circ}$. For larger branch angles, rupture continues along the main fault but only propagates for a short distance along the branch fault before terminating. The two possible branch geometries based on the mapping and interpretations by Potter et al. (2004) and Brocher et al. (1998) are highlighted in Figure 7. Based on the constant prestress results with elastic off-fault material behavior, the only scenario for dynamic branch activation with continued rupture along the splay fault is a rupture propagating updip along the SCF at a supershear speed and reaching a steeply dipping fault such as the Boomerang fault. Activation of a conjugate eastward dipping normal fault such as the Windy Wash fault is unlikely.

\section{Elastic Off-Fault Material Response}

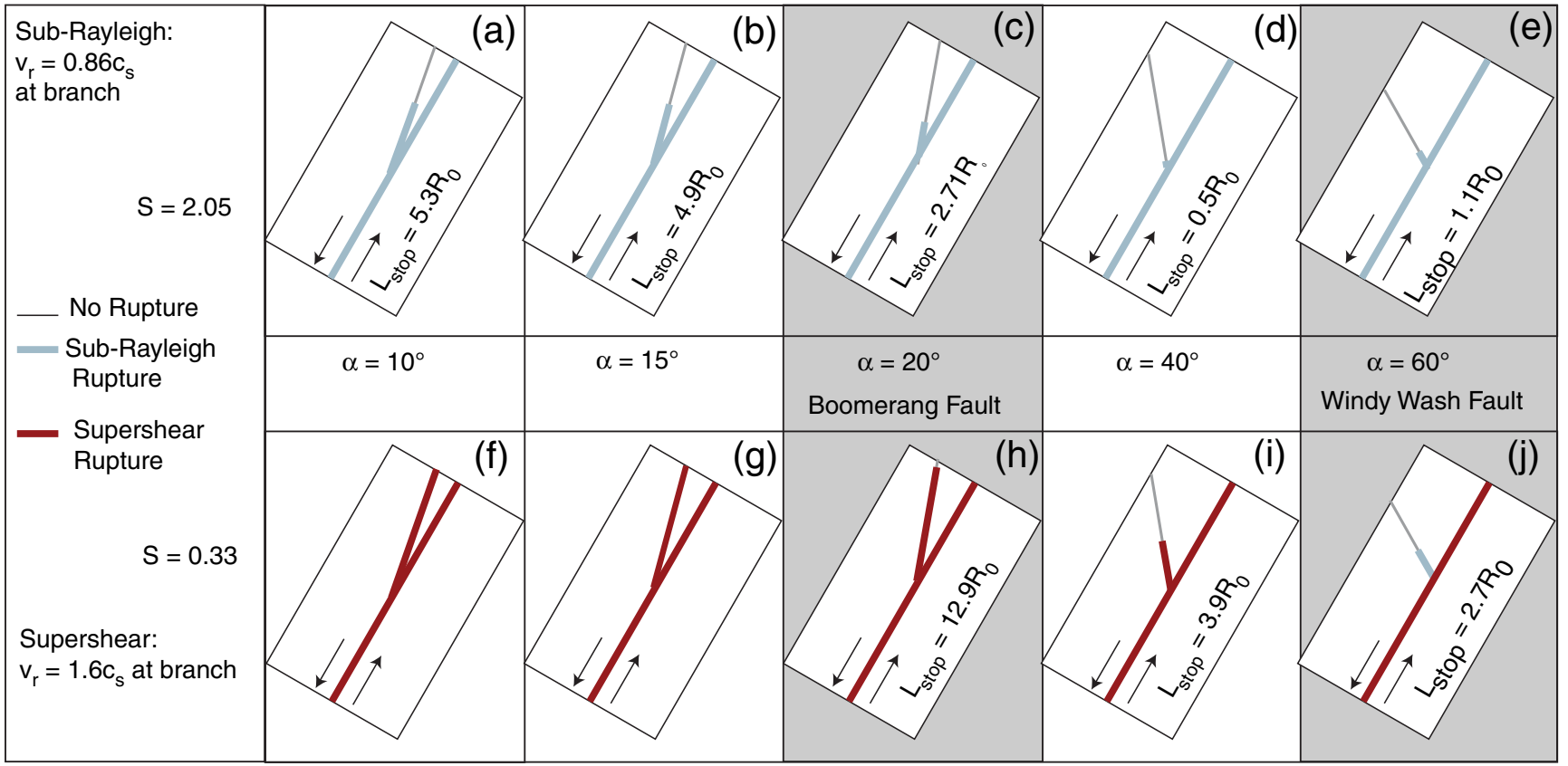

Figure 7. Branching results for constant prestress with elastic off-fault response for branch angles ranging from $10^{\circ}$ to $60^{\circ}$. The color version of this figure is available only in the electronic edition. 
Elastic-Plastic Off-Fault Material Response

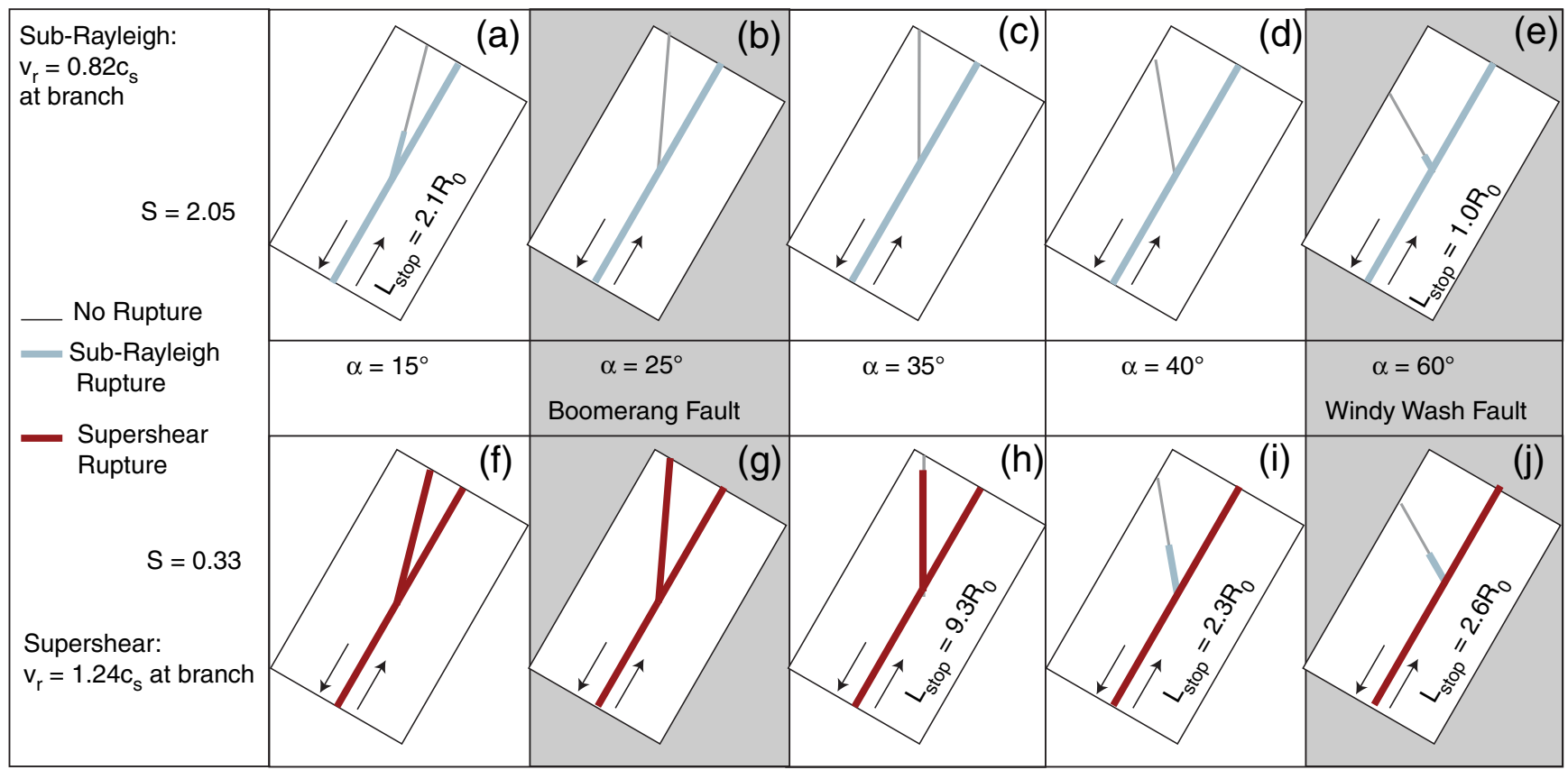

Figure 8. Branching results for constant prestress states with inelastic off-fault material response allowed for branch angles ranging from $15^{\circ}$ to $60^{\circ}$. The color version of this figure is available only in the electronic edition.

Inelastic Off-Fault Material Response. Figure 8 summarizes the dynamic branch activation results including elastic-plastic off-fault response. We use a DP yield condition with dilation, $\beta=0.29$, internal friction, $\mu=0.58$, and cohesion, $b=0$, to include the inelastic off-fault response. The primary effect of incorporating inelastic off-fault material response during dynamic rupture propagation is a reduction in the rupture velocity at the branching junction compared to the elastic case for the same rupture propagation distances. This effect is noted in Templeton and Rice (2008), and Templeton (2009) further investigated how energy dissipated by inelastic deformation can limit the speed of rupture propagation for sub-Rayleigh rupture. The velocity at the branching junction for the low stress-drop $\left(\Delta \tau /\left(-\sigma_{n}\right)=\right.$ $0.10)$ sub-Rayleigh rupture scenario was reduced to $0.82 c_{s}$ from $0.86 c_{s}$ by the inelastic off-fault deformation. The lower rupture velocity at the branch junction and plastic off-fault deformation resulted in fewer cases with branch fault activation. For all branch angles $\alpha \leq 60^{\circ}$, rupture continues along the main fault past the branch junction, and brief fault activation occurs only for $\alpha=15^{\circ}$ and $\alpha=60^{\circ}$. The velocity at the branching junction for the high stress-drop $\left(\Delta \tau /\left(-\sigma_{n}\right)\right.$ $=0.24$ ) supershear rupture scenario was reduced to $1.24 c_{s}$ from $1.6 c_{s}$ by the inelastic off-fault deformation. Supershear branch activation with rupture continuation along the main fault occurs along branches with angles $15^{\circ}$ and $25^{\circ}$. For larger branch angles, rupture continues along the main fault and propagates for a short distance along the branch fault before terminating. Two possible branch geometries based on surface mapping and interpretations of seismic reflection surveys are highlighted in Figure 8. The elasticplastic branching results also indicate that the only likely scenario for branch activation is a supershear rupture encountering a steeply westward dipping fault such as the Boomerang fault on the extensional side of the SCF.

Figure 9 shows the plastic strain generated near the branching junction for the three cases of branch activation with supershear rupture. Activation of the branch reduces the amount of plastic strain generated along the main fault, particularly so for the most shallow branch angles. This reduction in extent of the plastic zone width corresponds with a reduction in the amount of plastic strain energy dissipated, as shown in Figure 10. There is also a brief increase in rupture velocity immediately past the branch junction for $\alpha=15^{\circ}$.

\section{Depth-Dependent Prestress Results}

The constant prestress analyses suggest that the most likely scenario for activation of a fault branch on the hanging wall of the SCF is a steeply westward dipping branch with an angle $\alpha \leq 25^{\circ}$ between the branched fault and the SCF. Using the finite element model shown in Figure 6b, the effects of branched fault activation on the ground motions at the potential repository site, $1 \mathrm{~km}$ west of the SCF and $200 \mathrm{~m}$ below the free surface, are determined. A splay fault dipping $80^{\circ}$ to the west intersecting the SCF at $3 \mathrm{~km}$ depth is considered. Rupture is initiated at $10 \mathrm{~km}$ depth by a sudden drop in shear stress and propagates updip toward the splay fault in the 

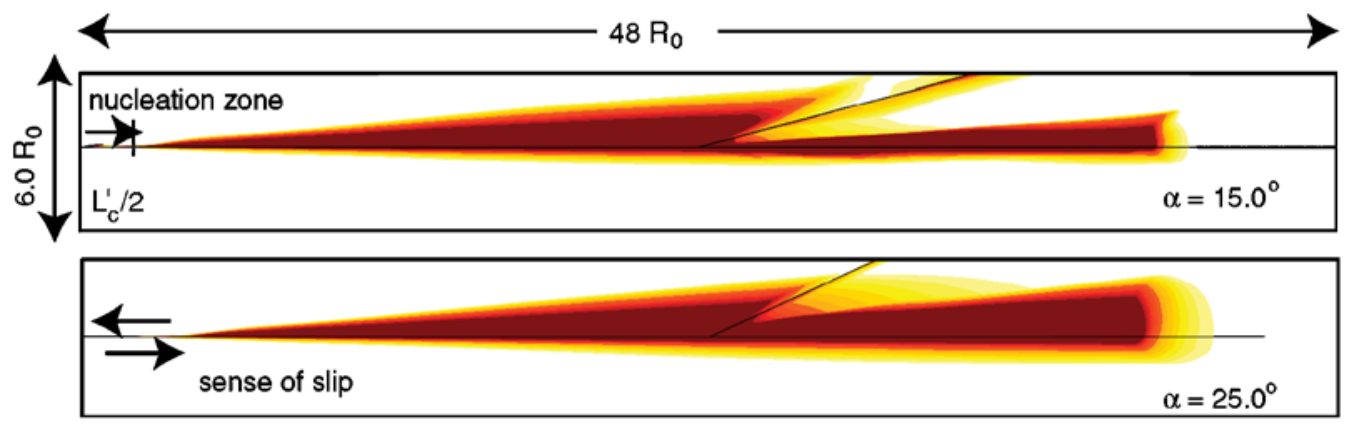

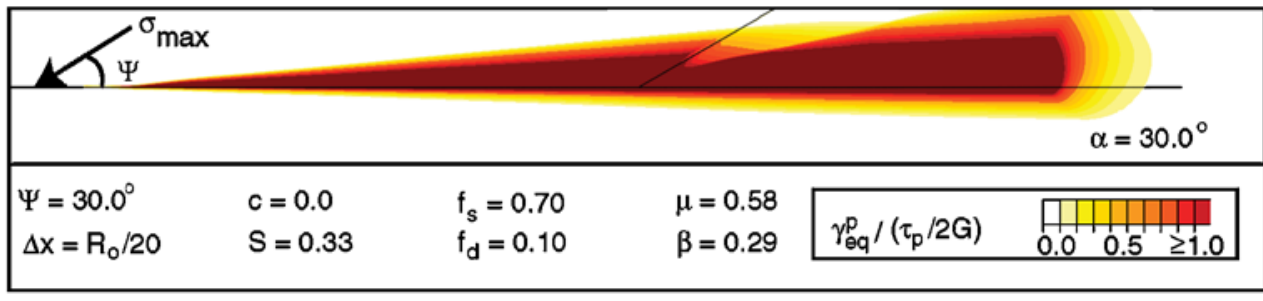

Figure 9. Contours of equivalent plastic strain surround the fault junctions for three cases of branch activation with supershear rupture at the branch junction. The color version of this figure is available only in the electronic edition.

hanging wall of the SCF. The slip-weakening distance, $D_{c}$, is $0.1 \mathrm{~m}$, which corresponds to an $R_{0}$ of $60 \mathrm{~m}$ at $8 \mathrm{~km}$ depth. Along the fault, the node spacing is $14 \mathrm{~m}$. Both the elastic and elastic-plastic constant stress model results indicate that the speed of rupture propagation at the branch junction must be supershear in order for continued rupture along the branch to occur. Friction coefficients for the large stress-drop case, $f_{s}=0.7$ and $f_{d}=0.1$, were used to produce a supershear rupture along the main fault. The stress drop at $3 \mathrm{~km}$ depth where the branch junction occurs is $18 \mathrm{MPa}$.

First, effects of branch fault activation with elastic offfault material response are considered. Rupture begins at depth along the SCF and propagates at a supershear velocity

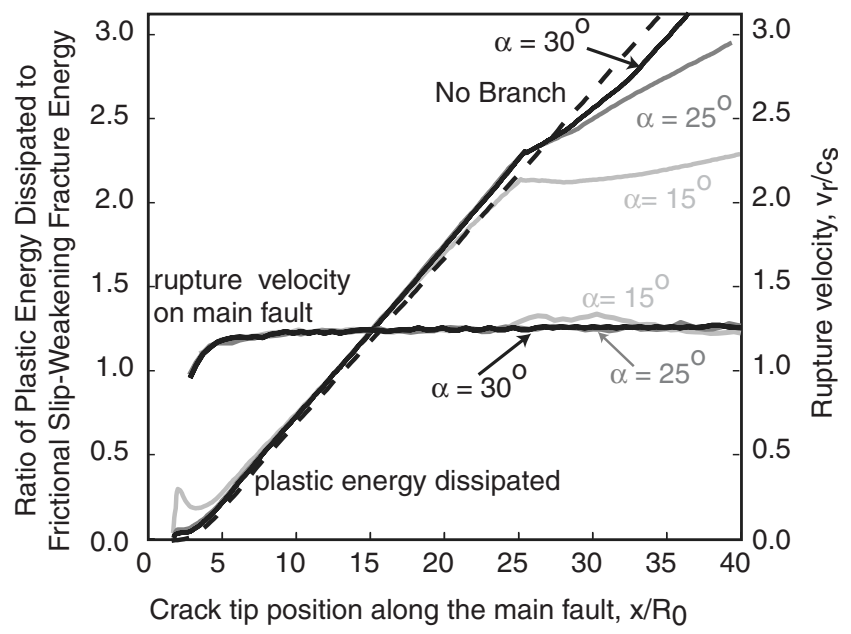

Figure 10. Variations in rupture velocity and plastic energy dissipated caused by branch activation. updip reaching the splay fault at a depth of $3 \mathrm{~km}$ with a propagation speed of $v_{r}=1.66 c_{s}$. Activation of the splay fault occurs, and supershear rupture propagates along the splay fault at $v_{r}=1.74 c_{s}$. Figure 11a,b shows the horizontal and vertical velocities at the repository site for the branch activation and for a reference case with no branch activation. The ground motions at the repository site are nearly identical until arrival of motions from rupture along the branched fault. There is a second large peak in vertical ground velocities at the repository site that corresponds to the passing of the Mach front generated by the supershear rupture along the splay fault. Although the PGV is not altered by the rupture along the branch, the second large peak in vertical velocity due to the branch activation does provide a substantial acceleration.

We also investigated the effects of off-fault inelastic deformation on the ground motions at the repository site. The DP yield criterion was included with $\mu=0.7, \beta=0.0$, and a cohesive strength of $b=7 \mathrm{MPa}$. Rupture begins at $10 \mathrm{~km}$ depth and propagates updip at a supershear velocity reaching the splay fault at a depth of $3 \mathrm{~km}$. Activation of the splay fault occurs, with rupture propagating at a supershear speed along the splay. Figures $11 \mathrm{c}, \mathrm{d}$ and 12 show the ground motions produced by branch activation within the elastic material compared with the ground motions produced within the elastic-plastic material. The energy dissipated by the inelastic response reduced the ground velocities experienced at the repository site. The peak horizontal ground velocities are reduced by $15 \%$ and the vertical peak velocities are reduced by $19 \%$. Also, the high accelerations (up to $\sim 16 g$ ) of the elastic case are substantially reduced, as evidenced by the much more gradual changes in ground velocity. Peak horizontal accelerations are reduced by $32 \%$ and peak vertical accelerations are reduced by $70 \%$. 
(a)

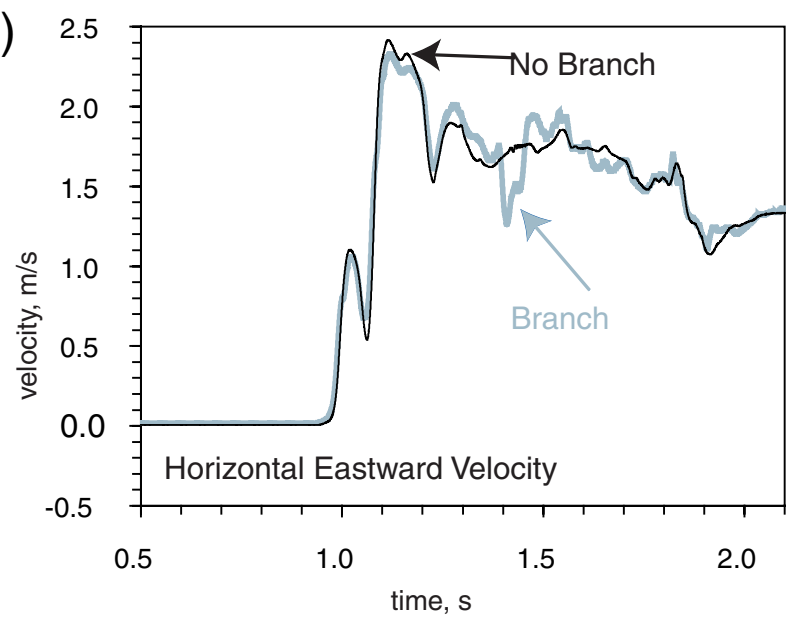

(c)

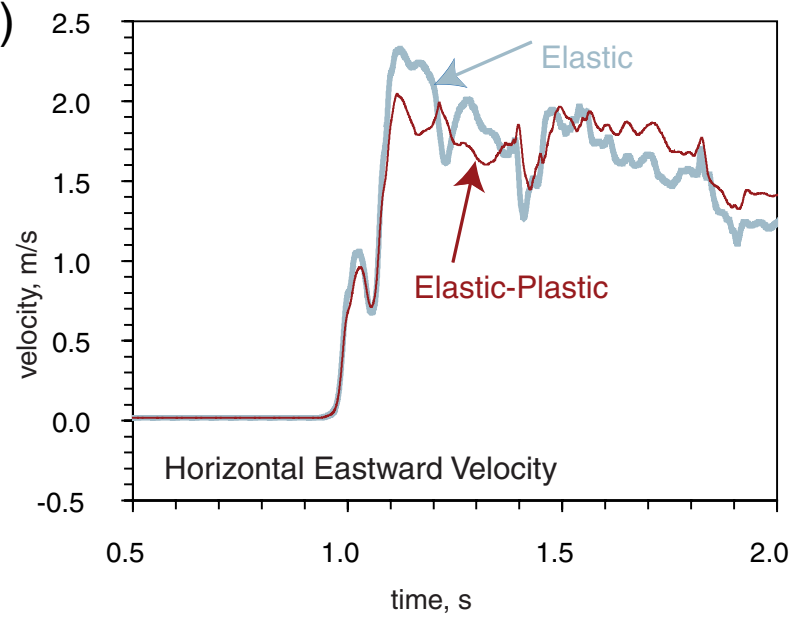

(b)

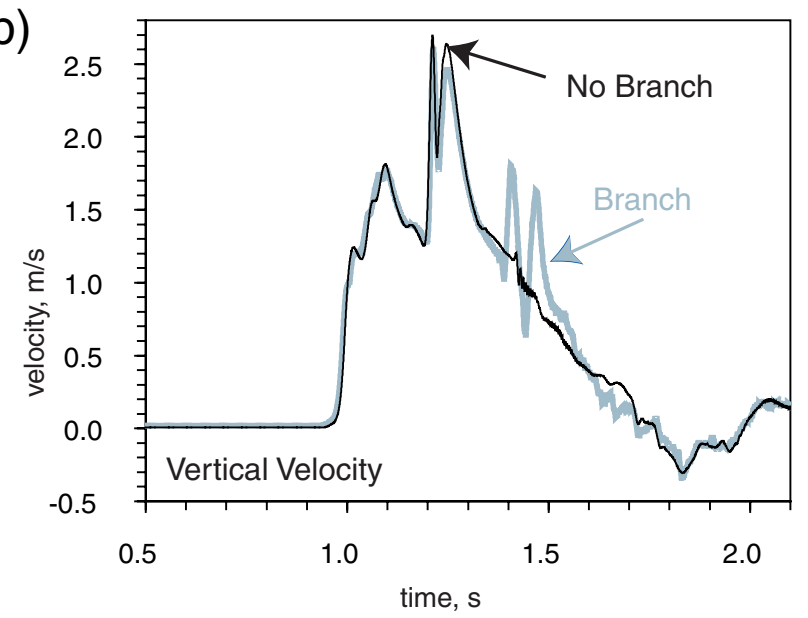

(d)

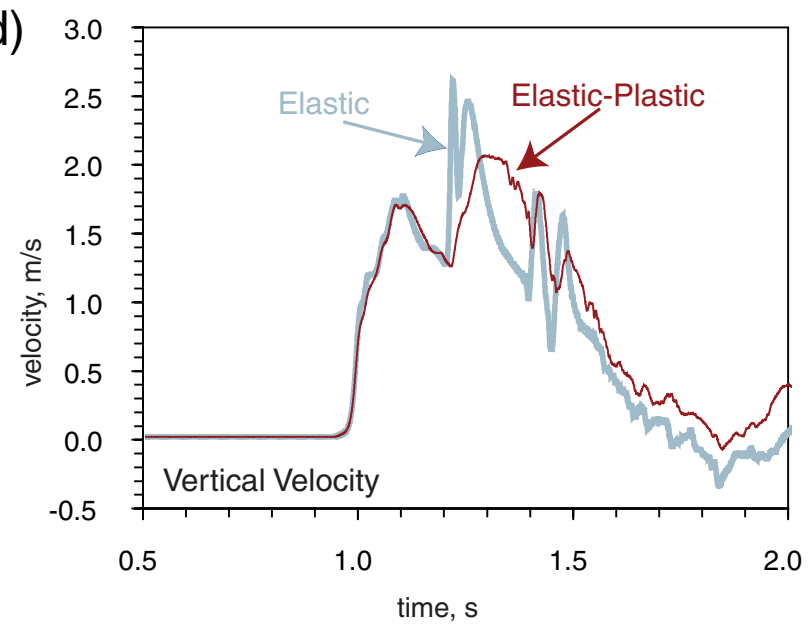

Figure 11. Effects of (a) and (b) branch activation and (c) and (d) elastic-plastic off-fault material response on vertical and horizontal ground velocities at the proposed repository site (1 km east of the SCF $200 \mathrm{~m}$ below the free surface) during a supershear rupture propagation along the SCF. The color version of this figure is available only in the electronic edition.

(a)

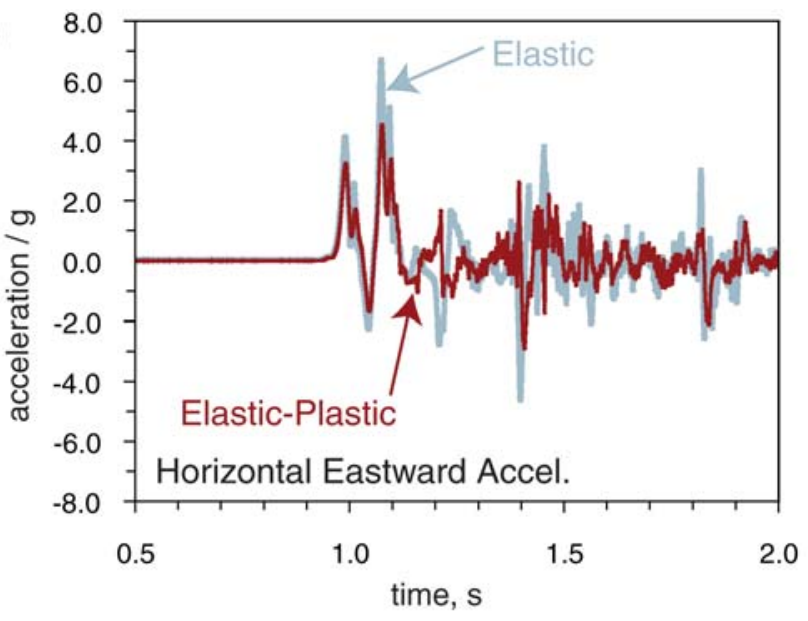

(b)

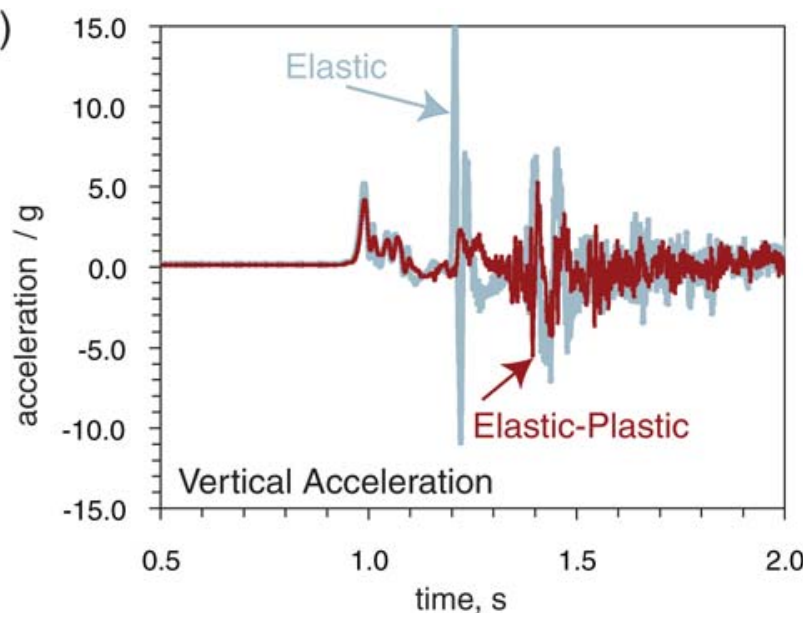

Figure 12. (a) Vertical and (b) horizontal ground accelerations for branch activation with elastic (light) and elastic-plastic (dark) off-fault material response at the proposed repository site ( $1 \mathrm{~km}$ east of the SCF $200 \mathrm{~m}$ below the free surface) during a supershear rupture propagation along the SCF. The color version of this figure is available only in the electronic edition. 


\section{Conclusions}

We investigated the likelihood of splay fault activation along the SCF, a normal fault in the vicinity of Yucca Mountain, Nevada. Based on the regional stress state in the area, the only likely candidates for branch activation in the hanging wall of the SCF are more steeply westward dipping intrablock splays that intersect the SCF at angles of $10^{\circ}-25^{\circ}$, such as the Boomerang fault. The rupture velocity for an earthquake propagating updip along the SCF must reach supershear speeds in order for dynamic branch activation to occur; however, there are no observations of supershear rupture during normal-faulting earthquakes. We found that branch activation can have significant effects on the ground motions at the proposed repository site, $1 \mathrm{~km}$ away from the SCF beneath the crest of Yucca Mountain. Supershear rupture along the branch segment can cause the repository site to experience a second peak in large vertical rupture velocities. Moderate reductions in horizontal and vertical velocity and large reductions in accelerations occur when elastic-plastic off-fault response is incorporated during rupture.

\section{Data and Resources}

All data used in this paper came from published sources listed in the references.

\section{Acknowledgments}

This research was supported by National Science Foundation (NSF) EAR award 0809610 and by the Southern California Earthquake Center (SCEC). SCEC is funded by NSF Cooperative Agreement EAR-0106924 and U.S. Geological Survey (USGS) Cooperative Agreement 02HQAG0008. The SCEC contribution number for this paper is 1267 .

\section{References}

ABAQUS (2005). ABAQUS Theory Manual, Version 6.5, Providence, Rhode Island.

Andrews, D. J. (1976). Rupture velocity of plane strain shear cracks, J. Geophys. Res. 81, no. 32, 5679-5687.

Andrews, D. J. (2005). Rupture dynamics with energy loss outside the slip zone, J. Geophys. Res. 110, B01307.

Andrews, D. J., T. C. Hanks, and J. W. Whitney (2007). Physical limits on ground motion at Yucca Mountain, Bull. Seismol. Soc. Am. 97, no. 6 , 1771-1792.

Ben-Zion, Y., and Z. Q. Shi (2005). Dynamic rupture on a material interface with spontaneous generation of plastic strain in the bulk, Earth Planet. Sci. Lett. 236, no. 1-2, 486-496.

Bhat, H. S., R. Dmowska, J. R. Rice, and N. Kame (2004). Dynamic slip transfer from the Denali to Totschunda faults, Alaska: Testing theory for fault branching, Bull. Seismol. Soc. Am. 94, no. 6, S202-S213.

Bhat, H. S., M. Olives, R. Dmowska, and J. R. Rice (2007). Role of fault branches in earthquake rupture dynamics, J. Geophys. Res. 112, B11309.

Brocher, T. M., W. C. Hunter, and V. E. Langenheim (1998). Implications of seismic reflection and potential field geophysical data on the structural framework of the Yucca Mountain-Crater Flat region, Nevada, Geol. Soc. Am. Bull. 110, no. 8, 947-971.

Carr, W. J. (1974). Summary of tectonic and structural evidence for stress orientation at the Nevada Test Site, U.S. Geol. Surv. Open-File Rept. $74-176$.
Colmenares, L., and M. Zoback (2002). A statistical evaluation of intact rock failure criteria constrained by polyaxial test data for five different rocks, Int. J. Rock Mech. Min. Sci. 39, no. 6, 695-729.

Davis, R. O., and A. P. S. Selvadurai (2002). Plasticity and Geomechanics, Cambridge U Press, Cambridge.

Day, W. C., R. P. Dickerson, C. J. Potter, D. S. Sweetkind, C. A. San Juan, R. M. Drake II, and C. J. Fridrich (1998). Bedrock geologic map of the Yucca Mountain area, Nye County, Nevada, U.S. Geol. Surv. Map I-2627, scale 1:24,000, $21 \mathrm{pp}$.

Day, W. C., C. J. Potter, D. S. Sweetkind, R. P. Dickerson, and C. A. S. Juan (1998). Bedrock geologic map of the central block area, Yucca Mountain, Nye County, Nevada, U.S. Geol. Surv. Map I-2601.

Dickerson, R. P., and R. W. Spengler (1994). Structural character of the northern segment of the Paintbrush Canyon fault, Yucca Mountain, Nevada, in Proc. of the 5th International High-Level Radioactive Waste Management Conf., Las Vegas, Nevada, 22-24 May.

Drucker, D. C., and W. Prager (1952). Soil mechanics and plastic analysis or limit design, Q. Appl. Math. 10, no. 2, 157-165.

Duan, B., and D. D. Oglesby (2007). Nonuniform prestress from prior earthquakes and the effect on dynamics of branched fault systems, J. Geophys. Res. 112, B05308.

Fliss, S., H. S. Bhat, R. Dmowska, and J. R. Rice (2005). Fault branching and rupture directivity, J. Geophys. Res. 110, B06312.

Ida, Y. (1972). Cohesive force across the tip of a longitudinal-shear crack and Griffith's specific surface energy, J. Geophys. Res. 77, no. 20, 3796-3805

Kame, N., J. R. Rice, and R. Dmowska (2003). Effects of prestress state and rupture velocity on dynamic fault branching, J. Geophys. Res. 108, no. B5, 2265 .

Lubliner, J. (1990). Plasticity Theory, Macmillan, New York.

Oglesby, D. D., S. M. Day, Y. G. Li, and J. E. Vidale (2003). The 1999 hector mine earthquake: The dynamics of a branched fault system, Bull. Seismol. Soc. Am. 93, 2459-2476.

Oglesby, D. D., D. Dreger, R. A. Harris, N. A. Ratchkovski, and R. Hansen (2004). Inverse kinematic and forward dynamic models of the 2002 Denali fault earthquake, Alaska, Bull. Seismol. Soc. Am. 94, S214-S233.

O’Neill, J. M., J. W. Whitney, and M. R. Hudson (1992). Photogeologic and kinematic analysis of lineaments at Yucca Mountain, Nevada; implications for strike-slip faulting and oroclinal bending, U.S. Geol. Surv. Open-File Rept. 91-623.

Palmer, A. C., and J. R. Rice (1973). Growth of slip surfaces in progressive failure of over-consolidated clay, Proc. Roy. Soc. Lond. Math. Phys. Sci. 332, no. 1591, 527-548.

Poliakov, A. N. B., R. Dmowska, and J. R. Rice (2002). Dynamic shear rupture interactions with fault bends and off-axis secondary faulting, J. Geophys. Res. 107, no. B11, 2295.

Potter, C. J., W. C. Day, D. S. Sweetkind, and R. P. Dickerson (2004). Structural geology of the proposed site area for a high-level radioactive waste repository, Yucca Mountain, Nevada, Bull. Geol. Soc. Am. 116, no. 7-8, 858-879.

Potter, C. J., R. P. Dickerson, and W. C. Day (1999). Nature and continuity of the Sundance fault, Yucca Mountain, Nevada, U.S. Geol. Surv. Open-File Rept. 98-266.

Rudnicki, J. W. (1984a). A class of elastic plastic constitutive laws for brittle rock, J. Rheol. 28, no. 6, 759-778.

Rudnicki, J. W. (1984b). Effects of dilatant hardening on the development of concentrated shear deformation in fissured rock masses, J. Geophys. Res. 89, 9259-9270.

Rudnicki, J. W. (2000). Diffusive instabilities in dilating and compacting geomaterials, in Multiscale Deformation and Fracture in Materials and Structures, T. J. Chuang and J. W. Rudnicki (Editors), Kluwer Academic, New York, 159-182 pp.

Rudnicki, J. W., and J. R. Rice (1975). Conditions for localization of deformation in pressure-sensitive dilatant materials, J. Mech. Phys. Solid 23, 371-394. 
Scott, R. B., and J. Bonk (1984). Preliminary geologic map of Yucca Mountain, Nye County, Nevada, with geologic sections, U.S. Geol. Surv. Open-File Rept. 84-494.

Scott, R. B., and B. P. Wernicke (1990). Tectonic setting of Yucca Mountain, Southwest Nevada, in Basin and Range Extensional Tectonics Near the Latitude of Las Vegas, Nevada, Geol. Soc. Am. Memoir.

Simonds, F. W., J. W. Whitney, K. F. Fox, A. R. Ramelli, J. C. Yount, C. M. Menges, R. P. Dickerson, and R. B. Scott (1995). Map showing fault activity in the Yucca Mountain area, Nye County, Nevada, U.S. Geol. Surv. Map I-2520.

Stepp, J. C., I. Wong, J. Whitney, R. Quittmeyer, N. Abrahamson, G. Toro, R. Youngs, K. Coppersmith, J. Savy, and T. Sullivan (2001). Probabilistic seismic hazard analyses for ground motions and fault displacement at Yucca Mountain, Nevada, Earthquake Spectra 17, 113-151.

Stock, J. M., J. H. Healy, S. H. Hickman, and M. D. Zoback (1985) Hydraulic fracturing stress measurements at Yucca Mountain, Nevada, and relationship to the regional stress field, J. Geophys. Res. 90, no. B10, 8691-8706.

Templeton, E. L. (2009). Effects of inelastic off-fault deformation on the dynamics of earthquake rupture and branch fault activation, Ph.D. Thesis, Harvard University.

Templeton, E. L., and J. R. Rice (2008). Off-fault plasticity and earthquake rupture dynamics: 1. Dry materials or neglect of fluid pressure changes, J. Geophys. Res. 113, no. B9, B09306.

Templeton, E. L., A. Baudet, H. S. Bhat, R. Dmowska, J. R. Rice, A. J. Rosakis, and C. E. Rousseau (2009). Finite element simulations of dynamic shear rupture experiments and dynamic path selection along kinked and branched faults, J. Geophys. Res. 114, B08304, doi $10.1029 / 2008 J B 006174$.

Viesca, R. C., E. L. Templeton, and J. R. Rice (2008). Off-fault plasticity and earthquake rupture dynamics: 2. Effects of fluid saturation, J. Geophys. Res. 113, B09307.

Zoback, M. L., and M. Zoback (1980). State of stress in the conterminous United States, J. Geophys. Res. 85, no. B11, 6113-6156.

School of Engineering and Applied Sciences

Harvard University

Cambridge, Massachusetts

(E.L.T.)

Department of Earth Sciences

University of Southern California

Los Angeles, California

(H.S.B.)

School of Engineering and Applied Sciences Department of Earth and Planetary Sciences

Harvard University

Cambridge, Massachusetts

(R.D., J.R.R.)

Manuscript received 20 May 2009 